\title{
A CONVERGÊNCIA JORNALÍSTICA POR QUEM A FAZ: UMA ANÁLISE DOS SENTIDOS RELATIVOS AOS PROCESSOS CONVERGENTES EM ENTREVISTAS COM JORNALISTAS DO DIÁRIO DOS CAMPOS
}

Journalistic convergence by those who do it: an analysis of the meanings related to the convergent processes in interviews with journalists from Diário dos

\section{Campos}

Convergencia periodística por quienes lo hacen: un análisis de los significados relacionados con los procesos convergentes en entrevistas con periodistas de Diário dos Campos

Ivan Bomfim

Professor do Programa de Pós-Graduação em Jornalismo da Universidade Estadual de Ponta

Grossa (UEPG)

ivanbp17@gmail.com

Ana Luisa Vaghetti Souza Jornalista graduada pela Universidade Estadual de Ponta Grossa (UEPG) analuisa.vsouza@gmail.com

\section{Resumo}

O presente trabalho busca compreender os diversos sentidos acerca da convergência jornalística a partir de entrevistas com profissionais do periódico Diário dos Campos, de Ponta Grossa (PR). Investigamos os discursos acionados pelos jornalistas que se encontram no meio do processo de convergência na mídia jornalística (JENKINS, 2009; SQUIRRA, 2012) em questão. Para tanto, utilizamos a Análise de Discurso de linha francesa (PÊCHEUX, 1995; 1997) com o intuito de delinear as formações discursivas que engendram a compreensão sobre as reformulações do jornalismo contemporâneo. Entre os resultados, notamos a hegemonia de discursos que se remetem à uma impossibilidade de conter a convergência, tendo por base concepção ideológica tecnicista.

Palavras-chave: Convergência Jornalística; Análise de Discurso; Diário dos Campos.

\section{Abstract}

The present work seeks to understand the different meanings about journalistic convergence based on interviews with professionals from the journal Diário dos Campos, from Ponta Grossa (PR). We investigate the speeches mobilized by journalists who are in the middle of the process of journalistic convergence (JENKINS, 2009; SQUIRRA, 2012) in the journalistic media in question. To this end, we use the French Discourse Analysis (PÊCHEUX, 1995; 1997) in order to outline the discursive formations that engender the comprehension of the 
reformulations of contemporary journalism. Among the results, we note the hegemony of discourses that refer to the impossibility of containing convergence, based on a technicist ideological conception.

Key words: Journalistic Convergence; Discourse Analysis; Diário dos Campos.

\section{Resumen}

Este artículo busca comprender los diferentes significados sobre la convergencia periodística a partir de entrevistas con profesionales del Diário dos Campos, de la ciudad de Ponta Grossa (PR). Investigamos los discursos desencadenados por los periodistas que están en medio del proceso de convergencia en los medios periodísticos (JENKINS, 2009; SQUIRRA, 2012) en cuestión. Para ello, utilizamos el Análisis del Discurso de la línea francesa (PÊCHEUX, 1995; 1997) para delinear las formaciones discursivas que engendran la comprensión sobre las reformulaciones del periodismo contemporáneo. Entre los resultados, observamos la hegemonía de los discursos que se refieren a la imposibilidad de contener la convergencia, basada en una concepción ideológica tecnicista.

Palabras clave: Convergencia Periodística; Análisis del Discurso; Diário dos Campos.

\section{INTRODUÇÃO}

O presente texto ${ }^{1}$ visa trazer um debate sobre a forma como a convergência jornalística está inserida no discurso dos profissionais que atuam no Diários dos Campos. O jornal pontagrossense mais antigo da cidade apresenta circulação impressa e um portal de notícias. A partir de autores como Jenkins (2009), Squirra (2012), Barbosa (2013), Bell e Owen (2017) e Pêcheux $(1995 ; 1997)$, este trabalho traz uma discussão teórica do contexto de transformações e adaptações que a produção jornalística tem enfrentado.

A convergência considerada um processo tecnológico, cultural e mercadológico traz influências para a rotina de produção, os produtos jornalísticos e a forma que o público consome e interage com o conteúdo. Por meio de entrevistas com profissionais do jornal (total de sete entrevistados), temos o intuito de analisar como essas transformações do jornalismo são vividas, entendidas e enfrentadas no dia a dia da redação, assim como a percepção sobre a produção noticiosa dos que nele atuam. Utilizamos também neste artigo da metodologia de Análise do Discurso de linha francesa a partir dos estudos de Pêcheux $(1975 ; 1997)$ para compreender melhor como os discursos dos jornalistas carregam sentidos e existem através da intersubjetividade.

O artigo é resultado de investigações realizadas pelo Grupo de Estudos em Mídias Digitais (GEMIDI) da UEPG, que desenvolve estudos sobre os processos de convergência em âmbito local, regional e nacional. 


\section{JORNALISMO DO INTERIOR/REGIONAL: O DIÁRIO DOS CAMPOS}

Para entender a dinâmica convergente na concepção dos jornalistas do Diário dos Campos, importa, inicialmente, debater o espectro do jornalismo produzido fora dos grandes centros urbanos. Conforme Aguiar (2016) e Assis (2013), embora existam diferenças conceituais, é possível abordar por um mesmo prisma o os "jornalismos" do interior e regional. O principal elemento de definição pode ser mirado na escala geográfica e sua relação com o fazer jornalístico (AGUIAR, 2016), visto que os veículos de imprensa refletem as preocupações do público ao qual são destinados.

Assis (2013, p.14) aponta que a principal característica do jornalismo do interior é relativa ao seu espaço de produção, "território que não o das capitais e o qual pode estar situado tanto na parte interna das unidades federativas, quanto no litoral e na fronteira etre estados (províncias, em alguns casos) ou na divisa de países”. A esta diferença estarão atreladas distintas lógicas e processos de produção, consumo e circulação do conteúdo noticioso, pois a comunidade na qual é desenvolvida a cobertura e à qual esta se endereça apresenta formações socioculturais, históricas, econômicas e políticas específicas. As preocupações, anseios, hábitos e valores do público constituem a pedra de torque dos veículos regionais/interioranos.

Abordar o impacto das reconfigurações do trabalho jornalístico pelos processos de convergência no Diário dos Campos demanda entender o contexto no qual o jornal está inserido. Publicado em Ponta Grossa, cidade de quase 350 mil habitantes $^{2}$ que se encontra a cerca de 100 quilômetros de distância da capital do estado (Curitiba), o periódico é um exemplo do que Assis (2013) define como imprensa do interior. O conceito abarca perspectiva mais ampla que a territorial - o interior, enquanto território, não deve ser entendido por viés estritamente geográfico:

Trata-se, aliás, de lugar onde situações ocorrem segundo lógicas culturais e sociais próprias, constituídas com particularidades que a própria geografia condiciona. Fazer jornalismo nesse ambiente, portanto, não consiste apenas em reproduzir padrões comuns aos grandes centros, mas em exercício que se dedica a encontrar as melhores maneiras - estratégias - para agir em cada realidade. Suas estruturas, suas rotinas, seus agendamentos, sua recepção e até mesmo os efeitos provocados pela informação de atualidade exibem, nesse âmbito, dinâmicas consideravelmente diferentes das identificadas em cenários nacional ou internacional. O lugar, por certo, condiciona o fazer jornalístico (ASSIS, 2013, p. 3-4).

2 <https://cidades.ibge.gov.br/brasil/pr/ponta-grossa/panorama>, acessado em 08/08/2019. 
A realidade do Diário dos Campos (ou DC) e dos jornalistas que nele atuam reflete sua existência enquanto empresa midiática localizada fora dos grandes centros nacionais. Há, neste sentido, uma dinâmica extremamente interessante entre a dimensão global entrelaçada ao desenvolvimento tecnológico (e, neste caso, aos processos de convergência) e o universo constituído pela dimensão histórica, representações, discursos, valores e conformações políticas e econômicos de uma determinada esfera regional.

Jornal impresso mais antigo em circulação na cidade, o DC antes era conhecido como O Progresso. Com início em 27 de abril de 1907, tinha edições semanais. A partir de 1913, iniciou circulação diária com o nome de Diário dos Campos. Cinquenta anos depois, assumiu algumas mudanças relacionadas ao lead e critérios como objetividade e imparcialidade nos textos, além da alteração do editorial da capa para a página 2 , e a utilização de fotos (BUCHOLDZ, 2007). Devido a problemas financeiros, o DC foi fechado em 1990, com a justificativa de que era necessário implantar novas tecnologias, principalmente na gráfica da empresa. O impresso retomou as atividades nove anos depois com a parceria do empresário Wilson Souza de Oliveira e o jornal Tribuna do Norte, de Apucarana (PR). Em 2000, a junção foi desfeita e o jornal é mantido até hoje somente pelo empresário. Nesse período, o Diário dos Campos introduziu transformações como informatização das redações, inovações de diagramação com softwares para designer gráfico, cadernos standard, páginas coloridas, além da redação ter sido estruturada basicamente por jornalistas diplomados (BUCHOLDZ, 2007).

O jornal circula atualmente pela região dos Campos Gerais (23 municípios, 950.325 habitantes), no Centro Sul do Paraná, estando presente na web através do site ${ }^{3}$ e da redes sociais $\left(\right.$ Facebook $^{4}$, Twitter ${ }^{5}$ e Instagram $\left.{ }^{6}\right)$. Conforme informações próprias, o DC objetiva atualização em tempo real, interatividade, ferramentas de pesquisa e serviço. Os princípios defendidos e executados no site são: tempo real (atualização ao longo do dia), interatividade, ação multiplataforma (newsletter, RSS e redes sociais) e serviços (indicadores econômicos, tempo, agenda cultural e empresarial, galeria de fotos e blog de eventos).

\footnotetext{
${ }^{3}$ www.diariodoscampos.com.br.

${ }^{4}$ https://www.facebook.com/diariodoscampos/

${ }^{5}$ https://twitter.com/diariodoscampos

${ }^{6}$ https://www.instagram.com/diariodoscampos/
} 


\subsection{Os processos de convergência na produção jornalística}

A discussão de convergência auxilia na reflexão sobre as transformações que o jornalismo tem enfrentado. Jenkins (2009, p.27), ao propor o termo cultura da convergência, refere-se "ao fluxo de conteúdos através de múltiplos suportes midiáticos, à cooperação entre múltiplos mercados midiáticos e ao comportamento migratório dos públicos dos meios de comunicação". Convergência é uma palavra usada para definir as transformações tecnológicas, mercadológicas, culturais e sociais que têm ocorrido na sociedade. O teórico defende que a circulação de conteúdos por meio de diferentes sistemas midiáticos depende da participação ativa dos consumidores.

Meu argumento aqui será contra a idéia de que a convergência deve ser compreendida principalmente como um processo tecnológico que une múltiplas funções dentro dos mesmos aparelhos. Em vez disso, a convergência representa uma transformação cultural, à medida que consumidores são incentivados a procurar novas informações e fazer conexões em meio a conteúdos midiáticos dispersos (JENKINS, 2009, p.27)

O autor sustenta que a convergência ocorre dentro dos cérebros de consumidores individuais e em suas interações sociais com outros. Em acordo, Squirra (2012) reflete sobre as manifestações jornalísticas a partir da evolução tecnológica. Para ele, o jornalismo vive uma crise de paradigmas, pois "não só os modelos de atuação comercial e de difusão de informação 'clássicos' não atingem mais plenamente seus públicos, como se explicita que os consumidores com poder de compra estão migrando para novas plataformas de acesso à informação" (SQUIRRA, 2012, p.107).

Surge a necessidade de o jornalismo criar novos modelos, estruturas e práticas para acompanhar o comportamento do público consumidor. Cádima (2015) diz que um jornalismo participativo "local", em rede e móvel está sustentado na emergência das novas gerações web. O contexto da convergência é marcado pelo potencial de interação entre jornalistas, tecnologias e cidadãos, criando necessidade de se pensar comunidades tecnologicamente nômades. "Essa questão, à luz dos dispositivos móveis, se, por um lado, evidencia os limites do jornalismo tradicional, vem possibilitar a emergência de novos ambientes colaborativos e 'locativos' de produção, reagregação e distribuição da informação e do conhecimento" (CÁDIMA, 2015, p.199)

A dimensão online e as redes sociais reconfiguram as práticas de apuração. Mesquita e Vizeu (2014) levantam hipótese de que há um novo agente que se envolve ou é envolvido nos 
processos, práticas e rotinas jornalísticas, possuindo capacidade de propagação da informação, possibilitada pelo acesso aos meios de produção e capacidade de transformação, na medida em que muda sua forma de ação e de comportamento ao longo do tempo. A manifestação do público é vista principalmente nas redes sociais, sendo chamado de "audiência potente" pelos autores, principalmente pelo poder que assume nos conteúdos já publicados nas redes e no poder de fonte consultiva para os próximos conteúdos.

Segundo Bell e Owen (2017) o jornalismo está enfrentando a terceira onda de transformação tecnológica. "A integração do meio jornalístico com plataformas sociais como Facebook, Twitter, Snapchat e Google acelerou. No mundo todo, há mais de 40 sites de mídias sociais e aplicativos de troca de mensagens pelos quais empresas jornalísticas podem atingir parte de seu público" (BELL; OWEN, 2017, p.52). Além disso, os veículos de imprensa têm investido em plataformas sociais como potencialidade para alcance de novos públicos.

Foi nos anos 1990 que o digital ganhou espaço vigorando com a expansão das conexões em rede, dos computadores, do surgimento da web, das melhorias nas infraestruturas de acesso, até a atual fase da ubiquidade das tecnologias e das redes e dispositivos móveis (BARBOSA, 2013). Os estudos da autora caracterizam o progresso do webjornalismo a partir de cinco principais gerações que marcaram a forma de produzir, circular e transmitir informação. A primeira geração é a fase da transposição ou reprodução em que os jornais apenas colocam na web o conteúdo semelhante ao do jornal impresso. A segunda geração, denominada como metáfora, já é quando os sites jornalísticos começam a empregar alguns recursos de interatividade (como espaços de fóruns, debates, comentários), hipertexto, entre outros. A terceira geração classificada como webjornalismo ou jornalismo digital engloba os produtos jornalísticos na web, bem como os recursos e tecnologias disponíveis para a disseminação dos conteúdos em dispositivos móveis (BARBOSA, 2013).

Quando surge o modelo de Jornalismo Digital em Base de Dados (JDBD) demarca-se a transição entre a terceira e a chamada quarta geração de evolução, na qual as bases de dados passa a fazer parte da apuração e produção jornalística. Por fim, a quinta e atual geração é definida como o auge do desenvolvimento das redes digitais, que é marcada por uma discussão de convergência jornalística, em que as mídias móveis tornam-se agentes propulsores de um novo ciclo de inovação, criando um contexto de emergência dos aplicativos jornalísticos autóctones (BARBOSA, 2013). 
Os processos de convergência de meios e linguagens, disseminados a partir do final do século XX, incitam a necessidade de análises acerca dessa realidade vivenciada em distintos âmbitos. Tais mudanças abarcam rotinas produtivas envolvidas no trabalho jornalístico, nas modificações operadas nas práticas jornalísticas, produtos que são gerados a partir de tais processos e forma do público consumir as informações geradas a partir dessa realidade que surge e se transforma nesses últimos anos.

\subsection{Metodologia: a Análise de Discurso}

Para a realização desta investigação, buscarmos o referencial da Análise de Discurso (ou AD) de linha francesa, com especial base nos estudos de Pêcheux (1995; 1997). Visto que intenciona-se "mostrar, em relação à organização textual, como se constrói a unidade do texto a partir do processo de produção do sentido e do sujeito" (ORLANDI, 2005, p. 71), é importante ter em perspectiva que a linguagem não é algo transparente, os enunciados são suscetíveis de tornarem-se outros, deslocando-se discursivamente. Segundo a autora, o discurso é um "efeito de sentido entre locutores", cuja estruturação é norteada pela construção de significados por meio da interação linguística. Para Maingueneau (1997, p. 21), o discurso dispõe "espaços de regularidades associados a condições de produção", tendo por características gerais ser: uma organização situada para além da frase; orientado; uma forma de ação; interativo; contextualizado; assumido por um sujeito; regido por normas; considerado apenas dentro da dinâmica de um interdiscurso. Marcadamente, o discurso só existe a partir da intersubjetividade - ou seja, da relação entre sujeitos.

$\mathrm{Na}$ consecução do trabalho, mobilizamos em especial o conceito de formação discursiva. Na perspectiva aqui contemplada, a FD é resultado de uma estrutura de formação social, que entrelaça posições políticas e ideológicas e se relaciona a formações ideológicas. Em uma explanação clássica, a formação discursiva é "aquilo que, numa formação ideológica dada, isto é, a partir de uma posição dada numa conjuntura dada, determinada pelo estado da luta de classes, determina o que pode e deve ser dito" (PÊCHEUX, 1997, p. 160). Destaca-se, contudo, ela não possui uma estrutura fechada, sendo "invadida" por sentidos de outras FDs e existindo somente a partir da interdiscursividade. Esta característica arregimenta os chamados elementos já pré-construídos e os saberes partilhados socialmente, funcionando para o apagamento da historicidade destes, realizada no sujeito. A concepção do que "pode" e do que "deve ser dito" em uma FD expõe uma conformação de regras acerca daquilo que é aceitável ser visibilizado - posto que também advoca o que "não pode" e "não deve ser dito" - tanto 
nos sentidos de paráfrase quanto das reformulações discursivas. Para Pêcheux (1995; 1997), é no âmago de uma FD que se concretiza o assujeitamento ou processo de subjetivação ideológica. $\mathrm{Na}$ perspectiva do teórico, é efetivado o fenômeno de ocultamento do interdiscurso presente no intradiscurso, de maneira que é perdida a percepção da "formasujeito" (o sujeito do discurso em cada formação discursiva) de vinculação aos elementos externos (inconscientes e ideológicos) que a compõem.

As formações discursivas constituem-se como "região de sentidos", que delimita fronteiras interpretativas dentro do texto. $\mathrm{O}$ que se encontra fora deste sentido é representativo de outra FD. Faz-se necessário apontar que as FDs não são blocos homogêneos de sentidos, por mais que pareçam dissimular como transparentes os discursos constituídos dentro delas. Pêcheux $(1995$; 1997) sustenta que, embora seja uma "região de sentidos" - ou justamente por isso -, a formação discursiva abriga tanto o processo de paráfrase quanto o de transformação de enunciados, não sendo por completo homogênea. Assim, são percebidos elementos contraditórios, que implicam sentidos distintos dos definidos como centrais a determinada FD.

O total de FDs em um texto é correspondente ao de sentidos definidos como nucleares, e que o sentido é proveniente de uma conformação ideológica. O sentido permitirá o estabelecimento de uma lógica a partir de um dito, na situação discursiva de uma configuração que não permite outra interpretação pelos sujeitos envolvidos, pois amparados por um mesmo céu ideológico. O dizer possui um "traço ideológico em relação a outros traços ideológicos. E isto não está na essência das palavras, mas na discursividade, isto é, na maneira como no discurso, a ideologia produz seus efeitos, materializando-se nele" (ORLANDI, 2005, p. 43). A ideologia, definida dentro dos estudos do discurso, processa um efeito de apagamento de sua própria existência ao escamotear a ação de interpretação, apresentando aquilo que é constituído subjetivamente como evidente, uma realidade objetiva. Para Pêcheux (1995; 1997), a ideologia deve ser entendida como um "dispositivo de subjetivação" ou interpelação do sujeito, visto que este acredita ser o autor dos sentidos que expõe, sem se dar conta dos processos relativos a estes, como a sujeição a determinados discursos e ideologias. O teórico diz que essa interpelação é estruturada pela identificação do sujeito a uma determinada formação discursiva, fundamentando uma unidade imaginária entre aquele que diz algo e o que é dito. A relação discurso-ideologia implica uma reafirmação do assujeitamento, inclusive a outras matrizes ideológicas constituídas social, jurídica e 
politicamente, sendo estas historicamente situadas. Em síntese, há uma estruturação de “esquecimentos" - apagamentos - dos determinantes dos sentidos visibilizados pelo sujeito.

Tendo em vista as temáticas relacionadas à $\mathrm{AD}$ de linha francesa, procedemos à análise das entrevistas com os jornalistas do Diário dos Campos.

\subsubsection{Convergência e jornalistas: formações discursivas}

Nosso intuito, neste primeiro contato com o material coletado no âmbito da pesquisa realizada pelo GEMIDI, foi analisar os discursos acerca dos processos de convergência jornalística visibilizados a partir da própria fala dos profissionais envolvidos e afetados pelo conjunto de mudanças da área. Foram realizadas entrevistas com sete jornalistas ${ }^{7}$, entre repórteres e editores, de diferentes editorias do Diário dos Campos entre o fim de 2017 e o início de 2018, implicando num corpus composto por sete textos.

De acordo com Morin (1973), a entrevista é uma ferramenta de pesquisa social, sendo que o "entrevistar" deve ser entendido como atitude de aproximação, relacionada fortemente à disposição do investigador no processo de escutar - com atenção especial ao interrelacionamento de perspectivas subjetivas do relato aos processos interpretativos do material de investigação. No presente trabalho, fizemos uso da entrevista semiestruturada, contudo é importante comentar que, das sete conversas, seis foram feitas por meio de contato telefônico e ou pessoal, mas uma só pode ser concretizada via email. Para Rosa e Arnoldi (2008), a entrevista em profundidade deve ser vista como um processo comunicativo de extração de informação por parte de um entrevistador, sendo que neste substrato informativo se encontra a biografia do entrevistado. Este tipo de entrevista requer uma preparação e uma estrutura especial que inclui, principalmente, um questionário organizado previamente, porém aberto às possibilidades de interação que surgem com o entrevistado.

O exame interpretativo do material coletado nas entrevistas possibilitou a constituição de um quadro de formações discursivas. Estas foram mapeadas a partir da identificação de diferentes matrizes de sentidos, a partir das quais as falas dos entrevistados dão visibilidade a discursos constituídos por paráfrases, em sua maioria, e também a sentidos que indicam possibilidades polissêmicas de compreensão dos processos de convergência. Delineamos as seguintes formações discursivas (que exemplificadas a partir de sequências discursivas mapeadas nas entrevistas):

\footnotetext{
${ }^{7}$ Os nomes dos profissionais não serão divulgados, sendo estes referidos com indicação numérica (entrevistado 1 , entrevistado 2, etc).
} 


\section{FD1: convergência inevitável}

FD de maior presença no material analisado. Visibilizada a partir de sentidos que sustentam que os processos de convergência jornalística são impossíveis de serem contidos, constituindo um caminho sem retorno para as empresas e para a própria profissão. Não são indicados, normativamente, valores de concordância ou repulsa à esta situação, embora os sentidos, no geral do corpus analisado, indiquem deslizamentos de preocupação com a questão. $\mathrm{O}$ trecho destacado apresenta sentidos que confluem para esta FD, perceptíveis pelos enunciados e termos em negrito:

O principal objeto é que na verdade hoje não tem como fugir disso né, tem muita gente que gosta do jornal impresso, tem muita gente que lê só pelas redes sociais, só pelo site, só na plataforma digital, então eu vejo que não tem como fugir disso. Tem que se pensar dessa forma, nessas múltiplas plataformas, e a gente pensa dessa maneira que eu comentei, de pensar material exclusivo para o site, pensar material diferente para o impresso, algo atrativo para o Facebook, como as entrevistas ao vivo, alguma coisa nesse sentido (entrevistado 3).

\section{FD2: convergência-modernidade}

A formação discursiva que equipara convergência e modernidade é uma das mais representativas no material analisado. A partir de uma concepção de tecnologia como avanço humano, a FD é dada a ver por sentidos que postulam os processos de convergência como concretização de uma "nova era" do jornalismo e mesmo da sociedade; a dimensão tecnológica é destituída, nessa perspectiva, de contradições, pois apresenta-se como elemento condicionante dos "novos tempos", no qual o jornalismo e o jornalista precisam estar em constante atualização - o que inclui a perspectiva de flexibilização da dimensão laboral.

A sequência discursiva destacada apresenta sentidos constituídos nessa perspectiva, especialmente percebidos pelas sequências discursivas destacadas, que indicam a tecnologia sendo adaptada ao aumento do volume de trabalho.

Em 2015 isso foi mudando, a plataforma continuou a mesma, mas a preocupação em postar matérias sobre algo que aconteceu naquele momento foi aumentando e nisso a gente começou a atualizar da redação, com repórter passando as informações de fora, para quem estivesse dentro da redação para atualizar. Em 2016 teve aquela preocupação e aí que nós entramos com o celular, com o Whatsapp , um 
celular moderno que o repórter pudesse levar para rua, tirar foto e mandar para redação.

[Isso tudo o jornal proporcionou?]

Proporcionou, o jornal disponibilizou um celular moderno para que o repórter levasse para rua, fizesse as fotos e mandasse para redação, para quem tivesse lá atualizar. Também criou um número de Whatsapp para que os próprios leitores ou as próprias pessoas que presenciassem alguma coisa pudessem mandar também foto e informações (...). Em 2017, tem menos de um mês que nós mudamos novamente a plataforma do site, as notícias ficaram muito mais disponibilizadas na página principal.É um site mais moderno , a fonte da leitura ficou mais tranquila, ele tá bem moderno e ele não fica sem ser alimentado por mais de uma hora, é uma regra, cada 15/20 minutos a gente precisa atualizar (entrevistado 2 ).

\section{FD3: convergência benéfica}

A concepção da convergência como elemento intrinsecamente benéfico se relaciona diretamente à estruturação da FD2 e da FD4 (convergência-profissionalismo). Os processos convergentes são, assim, afirmados como implicadores de melhorias do jornalismo como um todo, tendo em vista que permitem nova relação dos profissionais com sua própria profissão, tanto em termos técnicos quanto sociais (e, por que não dizer, imaginários e ideológicos).

\section{FD4: convergência-profissionalismo}

Uma nova fase do jornalismo no qual este se torna mais profissional é a principal matriz de sentidos da FD4. A uma ideia geral de aperfeiçoamento da atuação dos profissionais com as modificações trazidas no seio da convergência. Salta aos olhos, neste sentido, o panorama de que a profissão tem dependência explícita dos avanços tecnológicos para ser exercida de maneira eficiente - o que relativiza elementos básicos da deontologia e do ethos jornalístico, fornecendo poderes quase míticos à tecnologia.

O trecho em destaque apresenta sequências relacionadas às FD3 e FD4:

[Quais são as mudanças mais perceptíveis em relação a questões mais práticas?]

Sim, não só na prática jornalística, acho que em tudo, né? É importante. Que nem eu te falei, antes você fazia uma coisa... se a gente voltar lá no passado, você escrevia meio que às cegas, né. Porque você tinha que identificar o teu público, talvez através de uma pesquisa, você não sabia se era aquilo, pra quem chegava, de que forma que chegava... hoje, essa convergência toda, ela permite a interação, ela permite cada vez mais que você consiga saber o que que as pessoas querem, a velocidade que elas querem, a forma que elas querem, e você consegue ter um retorno 
se aquilo realmente tá chegando da forma que você gostaria que chegasse .

[Você vê esse feedback como um avanço dentro do jornalismo?]

Sim, com certeza, é um avanço. E pode avançar cada vez mais, sabe? Tem como avançar, tem como melhorar cada vez mais (entrevistado 6).

A fala do entrevistado evidencia, de maneira quase didática, as duas matrizes de sentido afirmadas. Tanto a convergência é algo certamente benéfico - sentido que se apoia na questão da interação e feedback do público/audiência, o que possibilitaria a produção de notícias "tecnicamente perfeitas" - quanto os avanços tecnológicos trazem, em seu bojo, um jornalismo aperfeiçoado, melhorado pelo desenvolvimento tecnológico.

\section{FD5: convergência fenômeno natural}

A ideia de convergência como um fenômeno "natural" é implicada por sentidos deterministas em relação ao desenvolvimento tecnológico e à realidade da profissão. São perceptíveis sentidos de resignação diante de uma "verdade imutável", como se a configuração do jornalismo seguisse um caminho evolutivo, de viés neutro e independente em relação aos demais contextos sociais, políticos, econômicos, etc.

\section{FD6: primazia do jornalismo online}

A FD6 apresenta perspectivas amparadas no consenso do jornalismo online como sendo o único tipo de jornalismo na atualidade. As diferenças entre dispositivos não são apenas distinções, mas demarcam aquilo que pode ser considerado efetivamente a profissão em si - e os jornalistas que não se adequam a esta "realidade" estão condenados. Este núcleo de sentidos apresenta-se como uma forma de radicalização de outras FDs, como FD1, FD2 e FD5.

O trecho destacado a seguir traz três sequências discursivas que expõem sentidos relacionados às duas últimas FDs:

Pelo processo mais de mercado que houve essa migração do impresso para o online, existe toda uma constatação que o online é uma plataforma hoje. Não se esquece o impresso, mas ele é uma plataforma a mais do online . Não sei precisar uma data exata ou um motivo, mas foi algo mais natural mesmo (entrevistado 1).

De acordo com as duas primeiras sequências discursivas, a primazia do jornalismo online é efetivada por ser uma "constatação" - ou seja, um fato inegável - e que o jornalismo 
impresso se constitui como uma plataforma que se soma ao universo online, sendo a ele subordinada. A terceira sequência, perceptível pelo trecho negritado " foi algo mais natural mesmo", expõe a ideia de que, por não haver um início demarcado, a situação é interpretada pelo entrevistado como um movimento orgânico, "puro", como se não houvesse um movimento estrutural de reconfiguração.

\section{FD7: redes sociais reconfiguram jornalismo}

A FD7 pode ser entendida como uma variação da FD6, com a principal diferença de ser visibilizada por sentidos que afirmam a primazia das redes sociais digitais na reconfiguração do jornalismo. Desta feita, relaciona-se também a outras FDs, especialmente por sublinhar as transformações da profissão na interação com o público/audiência (FD9), mas não se estrutura especificamente por vieses de compreensão positiva ou negativa, podendo ser percebida a partir das duas perspectivas. O trecho destacado é elucidativo neste sentido:

\footnotetext{
[Em que processo da produção a convergência se torna importante?]

Principalmente no processo das redes sociais, acesso aos portais de transparência. Aí também teve uma convergência, na questão do modo de se produzir jornalismo, usar o smartphone para se produzir um texto, um vídeo, uma foto. Isso também faz parte da convergência. Os repórteres costumam usar isso na produção das hard news. Esse processo está bem mais dinâmico, manda informações, joga para o home do jornal pelo celular, compartilha nas redes sociais. Estamos acostumados no celular, isso faz parte da convergência. Esse processo de mandar na hora a informação pela facilidade do celular. Não existe alguém específico para as redes sociais, na redação todo mundo publica e compartilha . A orientação é sempre fazer uma chamada mais atrativa para as redes, tentar colocar em tag os personagem para elevar a audiência, contudo é só uma orientação e não um padrão necessariamente. Acho que precisamos de um padrão porque senão fica meio perdido (...). Quando é repórter a questão da audiência é mais no achômetro, mas quem é chefe de redação monitora toda essa questão da audiência e percebe que muitos acessos são pela própria home do jornal e Google (trabalhamos com palavra chave justamente por isso) (entrevistado 2).
}

As sequências discursivas apresentadas trazem o panorama de uma redação na qual a dinâmica das redes sociais implica mudanças nas formas de produção e publicação do material noticioso, o que acarreta novas formas de pensar a atuação como repórter ou editor. 
Destaque-se também as transformações na própria organização da redação, que acompanha constantemente os índices de audiência, expostos pelas métricas de acesso aos conteúdos.

\title{
FD8: convergência problemática
}

A convergência é uma fase/processo que traz diversas dificuldades aos jornalistas, de acordo com os panoramas imbricados nos sentidos desta FD. A maioria dos sentidos aqui apontam para complexidades relacionadas à adaptação dos profissionais (especialmente os mais antigos) às novas configurações tecnológicas. Ademais das dificuldades com a tecnologia, outros elementos também são perceptíveis, como no caso do entrevistado 4, que expõe preocupações com a conservação do material produzido pelo Diário dos Campos trazendo à baila apreensões com a preservação da memória do jornal e do trabalho realizado pelos jornalistas.

\begin{abstract}
Acho importante falar de jornalismo online, e gostaria de apontar para um aspecto essencial, o de que o jornalismo online some com as informações. Isso acontece com muita frequência, os sites mudam, trocam layout e formato e acabam perdendo as notícias anteriores . É bem mais fácil achar uma matéria do jornal impresso do que do jornal online. Simplesmente a gente publica as notícias, esquece o que produzimos, as notícias somem quando há troca de servidor dos portais, ou seja, não há uma preocupação com a memória do jornalismo. Problema sério de apagar nossa história, jornalismo online veio para o imediato, mas não veio para perenidade (entrevistado 4).
\end{abstract}

\section{FD9: convergência com o leitor}

Uma das matrizes de sentido mais relacionadas ao que podemos denominar como omínio discursivo da convergência - dimensão de discursos enredados no conceito de onvergência - é constituída pela FD convergência com o leitor. Os sentidos evidenciados na nunciação da forma-sujeito desta matriz indicam que os processos convergentes extrapolam domínio jornalístico, sendo compartilhados com o público/audiência. Assim sendo, não é exagero dizer que a concepção de Jenkins (2009) de que a convergência deve ser entendida como processo cultural é marcante na constituição dos sentidos que perfazem esta FD, mesmo que esta perspectiva acadêmica não seja exposta de maneira "direta" pelos profissionais porém, indicando uma compreensão complexificada dos processos convergentes. 
A FD10 é delineada a partir da conformação de sentidos que trazem a preocupação comercial como principal força-motriz da convergência. O impacto da reconfiguração tecnológica no campo jornalístico e na profissão é eclipsado diante da perspectiva instrumental das mudanças, que visariam somente a maximização dos lucros. É marcante que a dimensão mercadológica deste núcleo seja exposta por meio de enunciados por vezes irônicos, que indicam interpretação cética acerca dos resultados reestruturação convergente do jornalismo, como na sequência discursiva exposta a seguir:

[O principal objetivo é] atingir o maior número de leitores, né. Parece que fica mais fácil. Todo mundo tem celular, tem isso, tem aquilo. É diferente do papel, que você tem que ir em uma banca, ou recebe por assinatura. É mais fácil, mais versátil. E pelo lado do jornal, a economia do papel, haha. [A economia] também para o futuro, porque você gastar dinheiro para imprimir é dinheiro que você deixa de gastar só no digital (entrevistado 5).

\subsubsection{A convergência jornalística como ideologia tecnicista}

A partir das formações discursivas mapeadas no contato com as entrevistas dos profissionais que atuam no Diário dos Campos, notamos que a compreensão dos processos de convergência conflui para uma perspectiva hegemônica: a convergência é um movimento inelutável, uma realidade que se impõe sem possibilidade de questionamento. Ademais de a própria FD de maior presença nos textos ser denominada em atenção à esta conformação discursiva (FD1), as outras FDs de destaque são constituídas no tensionamento justamente de discursos que sustentam esse horizonte de entendimento. A FD2 estabelece a convergência como exemplo da "modernidade", ou seja, como processo subjacente à chegada do “jornalismo do futuro". A FD3, por sua vez, traz discursos de verve panegírica, apontando as benesses aqui consideradas intrínsecas à marcha convergente em relação ao jornalismo. A FD4, ao equiparar convergência e profissionalismo, aprofunda os sentidos de uma vinculação automática entre a ampliação das atividades dos profissionais e uma melhor concretização do trabalho jornalístico. Por sua vez, a FD5 enceta a ideia de que há uma "naturalidade" no processo de convergência jornalística, eliminando qualquer espaço de questionamento acerca da questão. Dentre as formações discursivas com menor visibilidade, FD6, FD7 e FD9 apontam para a convergência como resultado da incorporação do jornalismo ao ambiente digital/online, com o impacto das redes sociais e mesmo do público. 
Apenas duas FDs são constituídas por sentidos que destacam elementos negativos da convergência. No caso da FD8 (convergência problemática), a preocupação é com as dificuldades relacionadas ao espectro dos processos, as problemáticas práticas que se apresentam com a adoção gradativa da tecnologia. No que tange à FD10 (convergênciainteresse mercadológico) a crítica se relaciona às próprias lógicas da ação convergente, entendida como estratégia cuja real motivação é puramente a lucratividade do negócio noticioso. Interessante que os sentidos de ironia aqui serve à exposição de uma descrença em relação aos discursos enaltecedores, como uma "incorreção" que teima em escapar à compreensão hegemônica, dando visibilidade às fraturas dos discursos articulados pela dimensão ideológica que sustentam uma supostamente inescapável realidade da convergência no jornalismo.

\section{CONSIDERAÇÕES}

Este texto apresenta um primeiro trabalho realizado pelo GEMIDI acerca de um extenso material coletado no decorrer do último ano para a análise dos processos de convergência jornalística. Procuramos realizar uma análise dos discursos trazidos pela fala dos jornalistas do periódico Diário dos Campos, visto que estes profissionais, dos mais novos aos mais experientes, se veem enredados em uma miríade de transformações em sua profissão.

Evidencia-se que a convergência não é “apenas" um processo tecnológico, mas cultural: as modificações são estruturais, demandando uma reorganização simbólica das atividades. A situação é trazida pelos diversos discursos que constituem matrizes de sentido acerca da nova "realidade", visto que, das perspectivas mais otimistas às mais pessimistas, apresenta-se como inegável a adaptação das formas de pensar e fazer o jornalismo - mesmo que estas transformações sejam impostas ou que as reconfigurações não sejam completamente visíveis aos sujeitos imbricados nela. É neste ponto que a $\mathrm{AD}$ pêcheuxtiana ajuda a compreender o entrelaçamento de concepções que conformam o universo discursivo da convergência jornalística: é necessário analisar os enunciados dos envolvidos nesse processo para além de uma dimensão instrumental do jornalismo. A instância jornalística, que envolve o campo e o ethos profissional, é complexificada a partir da visibilização de sentidos que entremeiam formações discursivas e ideológicas, numa multiforme relação estabelecida entre materialidade, cognição e imaginário. 
Seguindo esse encadeamento, percebemos a hegemonia de formações discursivas estruturadas por uma dimensão ideológica da convergência, sendo esta instituída ideacionalmente como inevitável. Importa lembrar que a ideologia, apagando sua própria existência, funciona como dispositivo de subjetivação, conformando-se uma dinâmica de assujeitamento. No material analisado, as FDs com maior visibilidade se instituem como sustentações diversas de uma mesma afirmativa.

As considerações dos profissionais acerca dos processos de convergência também podem ser pensadas em relação ao universo de jornalismo do interior. Em suas características próprias, a prática noticiosa realizada neste espaço expõe as distintas formas de concepção da realidade, constituídas no bojo de tradições, valores e discursos regionalizados. O "surgimento" do horizonte tecnológico-convergente no âmbito do trabalho fomenta concepções que precisam ser analisadas em específico, levando-se em conta que, embora interiorana, Ponta Grossa é uma cidade média, apresentando um nível de urbanização considerável, resultado de relevância histórica como entroncamento de vias rodoviárias e ferroviárias e de sua constituição como polo industrial.

Disso decorrem algumas observações. Ao proceder à convergência, o veículo em questão, cujo foco é uma cobertura regionalizada, fomenta uma série de discursos que têm na ideia de "modernização" sua principal força - esta podendo ser pensada na ambiguidade de uma localidade que engendra elementos urbanos e rurais, numa dinâmica que tem latente a oposição desenvolvimento/atraso, resultado de um discurso histórico relacionado à ideologia da modernidade. É possível conjecturar que a pouca visibilidade das FDs que apontam sentidos negativos tenha a ver com essa situação. Ao mesmo tempo, a desconfiança em relação aos processos e lógicas convergente expõem sentidos que grassam entre preocupações práticas e descrédito com discursos salvadores, ou seja, a recusa da pronta aceitação da tecnologia como panaceia, numa contestação perspectiva tecnicista prevalente. A própria argumentação da impossibilidade de "fugir" do processo convergente denota uma capitulação em relação à sua efetivação, mas não a comunhão com sua racionalidade. Nesta consideração, as maneiras pelas quais os contexto sociais, culturais e históricos interagem com os discursos da modernização tecnológica entranhados no universo da convergência jornalística se impõem como um desdobramento a ser enfocado em próximas análises. 


\section{REFERÊNCIAS}

AGUIAR, Sonia. Territórios do jornalismo: geografias de mídia local e regional no Brasil.

Petrópolis: Vozes; Rio de Janeiro: Editora PUC Rio, 2016.

ASSIS, Francisco de. Por uma geografia da produção jornalística: a imprensa do interior. Intercom: Anais do XXXVI Congresso Brasileiro de Ciências da Comunicação - Manaus, AM - 4 a $7 / 9 / 2013$.

BARBOSA, Suzana. Jornalismo convergente e continuum multimídia na quinta geração do jornalismo nas redes digitais. In: CANAVILHAS, J. (Org). Notícias e Mobilidade. O Jornalismo na Era dos Dispositivos Móveis.Covilhã, PT: Livros LabCOM, 2013. p. 33-54.

BELL, Emily. OWEN, Taylor. A imprensa nas plataformas: Como o vale do silício reestruturou o jornalismo. Revista de Jornalismo ESPM. Vol 20. N 6. Dez. 2017.

BUCHOLDZ, Alessandra. Diário dos Campos: Memórias de um jornal centenário. Ponta Grossa: Ed. UEPG, 2007.

CÁDIMA, Francisco. Novas Convergências Digitais: Mídia, Humanidades e Artes. Revistas Novos Olhares, Vol. 4.1.2015.

INDURSKY, Freda. Remontando de Pêcheux a Foucault: uma leitura em contraponto. Anais do I Seminário de Estudos em Análise do Discurso (SEAD): Porto Alegre, 2003.

JENKINS, Henry. Cultura da Convergência. São Paulo: Aleph, 2009.

MAINGUENEAU, Dominique. Novas tendências em Análise do Discurso. Campinas: Pontes, 1997.

MESQUITA, Giovana; VIZEU, Alfredo. A audiência potente e as novas relações no jornalismo. Estudos em Jornalismo e Mídia, v. 11, n. 2, p. 596-607, 2014.

MORIN, Edgar. A entrevista nas Ciências Sociais, na rádio e na televisão. In: MOLES, Abraham et al. Linguagem da cultura de massa. Petrópolis: Vozes, 1973.

ORLANDI, Eni. Análise de Discurso: princípios e procedimentos. Campinas: Pontes, 2005.

PÊCHEUX, Michel. O discurso: estrutura ou acontecimento. Campinas: Pontes, 1995.

1997. Semântica e discurso: uma crítica da afirmação do óbvio. Campinas: Unicamp,

ROSA, Maria.; ARNOLDI, Marlene. A entrevista na pesquisa qualitativa: mecanismos para validação dos resultados. Belo Horizonte: Editora Autêntica, 2008.

SQUIRRA, Sebastião. Convergências tecnológicas, mídias aditivas e espiralação de conteúdos jornalísticos. In: D’ANDRÉA, Carlos; LONGHI, Raquel. (Orgs.). Jornalismo Convergente: reflexões, apropriações, experiências. Florianópolis: Insular, 2012. 
Professor do Programa do Pós-Graduação em Jornalismo e do Departamento de Jornalismo da Universidade Estadual de Ponta Grossa (UEPG). Doutor em Comunicação e Informação pela Universidade Federal do Rio Grande do Sul (UFRGS), com pós-doutorado em Ciências da Comunicação pela Unisinos. É um dos coordenadores do Grupo de Estudos e Pesquisas em Mídias Digitais (GEMIDI).

Ana Luisa Vaghetti Souza

Estudante de Pós-Graduação em Comunicação Digital e E-branding da Pontifícia Universidade Católica do Paraná (PUCPR). Graduada em Jornalismo pela Universidade Estadual de Ponta Grossa (UEPG). Bolsista CNPq e participante do Grupo de Estudos e Pesquisas em Mídias Digitais (GEMIDI) entre 2015 e 2018.

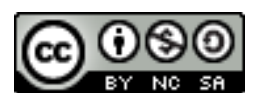

Esta obra está licenciada com uma Licença

Creative Commons Atribuição-NãoComercial-CompartilhaIgual 4.0 Internacional 